\title{
2004s-47 \\ Output and Wages with Inequality Averse Agents
}

\author{
Dominique Demougin, Claude Fluet, \\ Carsten Helm
}

\begin{tabular}{c}
\hline Série Scientifique \\
Scientific Series
\end{tabular}

Montréal

Septembre 2004

(C) 2004 Dominique Demougin, Claude Fluet, Carsten Helm. Tous droits réservés. All rights reserved.

Reproduction partielle permise avec citation du document source, incluant la notice (C)

Short sections may be quoted without explicit permission, iffull credit, including (C) notice, is given to the source.
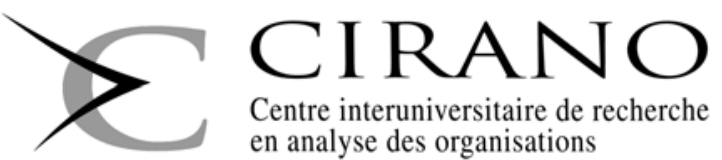

Centre interuniversitaire de recherche en analyse des organisations 


\section{CIRANO}

Le CIRANO est un organisme sans but lucratif constitué en vertu de la Loi des compagnies du Québec. Le financement de son infrastructure et de ses activités de recherche provient des cotisations de ses organisations-membres, d'une subvention d'infrastructure du Ministère du Développement économique et régional et de la Recherche, de même que des subventions et mandats obtenus par ses équipes de recherche.

CIRANO is a private non-profit organization incorporated under the Québec Companies Act. Its infrastructure and research activities are funded through fees paid by member organizations, an infrastructure grant from the Ministère du Développement économique et régional et de la Recherche, and grants and research mandates obtained by its research teams.

PARTENAIRE MAJEUR

Les organisations-partenaires / The Partner Organizations

. Ministère du Développement économique et régional et de la Recherche [MDERR]

PARTENAIRES

. Alcan inc.

. Axa Canada

. Banque du Canada

. Banque Laurentienne du Canada

. Banque Nationale du Canada

. Banque Royale du Canada

. Bell Canada

. BMO Groupe Financier

. Bombardier

. Bourse de Montréal

. Caisse de dépôt et placement du Québec

. Développement des ressources humaines Canada [DRHC]

. Fédération des caisses Desjardins du Québec

. GazMétro

. Hydro-Québec

. Industrie Canada

. Ministère des Finances du Québec

. Pratt \& Whitney Canada Inc.

. Raymond Chabot Grant Thornton

. Ville de Montréal

. École Polytechnique de Montréal

. HEC Montréal

. Université Concordia

. Université de Montréal

. Université du Québec à Montréal

. Université Laval

. Université McGill

. Université de Sherbrooke

Associe A :

. Institut de Finance Mathématique de Montréal (IFM²)

. Laboratoires universitaires Bell Canada

. Réseau de calcul et de modélisation mathématique $\left[\mathrm{RCM}^{2}\right]$

. Réseau de centres d'excellence MITACS (Les mathématiques des technologies de l'information et des systèmes complexes)

Les cahiers de la série scientifique $(\mathrm{CS})$ visent à rendre accessibles des résultats de recherche effectuée au CIRANO afin de susciter échanges et commentaires. Ces cahiers sont écrits dans le style des publications scientifiques. Les idées et les opinions émises sont sous l'unique responsabilité des auteurs et ne représentent pas nécessairement les positions du CIRANO ou de ses partenaires.

This paper presents research carried out at CIRANO and aims at encouraging discussion and comment. The observations and viewpoints expressed are the sole responsibility of the authors. They do not necessarily represent positions of CIRANO or its partners. 


\title{
Output and Wages with Inequality Averse Agents
}

\author{
Dominique Demougin", Claude Fluet", Carsten Helm ${ }^{*}$
}

\section{Résumé / Abstract}

Nous analysons un environnement de travail à deux tâches avec des individus neutres au risque, mais avec de l'aversion pour l'inégalité. L'effort de l'agent affecté à la tâche 2 est vérifiable, mais ne l'est pas pour l'agent dans la tâche 1 . L'agent 1 est donc rémunéré sur la base d'un contrat incitatif, ce qui lui procure une rente qui est source de désutilité pour l'autre agent. L'aversion pour l'inégalité a un effet sur les contrats optimaux des deux agents. Elle réduit l'effort, le salaire et le gain net de l'agent 1, mais a des effets ambigus sur l'agent 2 selon que les niveaux d'effort dans les deux tâches sont des substituts ou des compléments dans la fonction de production de l'entreprise. Cependant, une plus grande aversion pour l'inégalité a toujours pour effet de réduire la production totale et donc la productivité moyenne du travail.

Mots clés : aversion pour l'inégalité, compression salariale, aléa moral, incitations

We analyze a two-task work environment with risk-neutral but inequality averse individuals. For the agent employed in task 2 effort is verifiable, while in task 1 it is not. Accordingly, agent 1 receives an incentive contract which, due to his wealth constraint, leads to a rent that the other agent resents. We show that inequality aversion affects the optimal contracts of both agents. Greater inequality aversion reduces the effort, wage and payoff of agent 1 , while the effects on the wage and effort of agent 2 depend on whether effort levels across tasks are substitutes or complements in the firm's output function. However, more inequality aversion unambiguously decreases total output and therefore average labor productivity.

Keywords: inequality aversion, wage compression, moral hazard, incentives

Codes JEL : D63; D2, J3, L2

\footnotetext{
* School of Business and Economics, Humboldt University Berlin, Spandauer Str. 1, D-10178 Berlin, Germany, Tel: +49 30 2093-1342, Fax: +49 30 2093-1343, email: demougin@wiwi.hu-berlin.de.

† Fluet: Université du Québec à Montréal, CRIPÉE and CIRANO (C.P. 8888, Succ. Centre-Ville, Montréal, H3C 3P8, Canada, email: claude-denys.fluet@ugam.ca.

\$ School of Business and Economics, Humboldt University Berlin, Spandauer Str. 1, D-10178 Berlin, Germany, Tel: +49 30 2093-1342, Fax: +49 30 2093-1343, email: helm@wiwi.hu-berlin.de
} 


\section{Introduction}

In a recent study, Brosnan and Waal (2003) analyzed the response of capuchin monkeys to unequal pay. In the baseline test, two monkeys received a token that could immediately be returned to the experimenter for a cucumber. The monkeys exchanged successfully in 95 per cent of the cases. In the next test, one monkey exchanged for cucumber and the other one for grapes. Now more than 40 per cent of the monkeys that were rewarded with cucumbers, the less favored reward, refused to exchange. The rejection rate even increased to 80 per cent when the other monkey received the better reward without any effort (i.e. without having to hand over a token).

There is by now a plethora of papers in economics arguing that rejection of unequal pay is not restricted to capuchin monkeys, but is probably just as typical of human beings. ${ }^{1}$ According to these studies, individuals are not entirely self-centered, but care about fairness and relative rewards. Thus, workers may envy those who get a better deal and suffer disutility from being treated 'unfairly'. Conversely, they may also have empathic preferences and dislike outperforming co-workers. In this paper we analyze some implications of other-regarding preferences for optimal contract design. If 'inequality aversion' differs between socio-economic systems - e.g., Europe versus the US - or even between corporate cultures, how would this be reflected in the organization of work?

We consider the situation of a firm employing risk-neutral and wealth constrained agents in two different tasks or occupations. In one task, effortrespectively a perfectly correlated signal-is verifiable. In the other task it is not, leading to moral hazard. For example, one may think of skilled and unskilled labor, where the activity of the latter is less complex and, therefore, relatively easy to verify. Alternatively, it may simply be that some activities are inherently more difficult to monitor than others; think of sales representatives versus employees working in-house. Similarly, the effort of a manager is probably more difficult to assess than that of a worker at a conveyor belt.

In such a framework, providing incentives is costly for the principal. The workers with non-verifiable effort - category 1 agents - must be motivated through some form of performance pay. This implies paying out rent because of the agents' wealth constraint. By contrast, workers with verifiable effort - category 2 agents - receive a fixed wage contract and no rent. If these workers are inequality averse, they suffer disutility from the other agents' rent and this requires compensation. This 'inequality premium' therefore increases the firm's costs of providing incentives to the agents with non verifiable effort.

\footnotetext{
${ }^{1}$ For recent surveys see Konow (2003), Camerer (2003) as well as Fehr and Schmidt (2003).
} 
Accordingly, we find that greater inequality aversion leads to smaller effort, wage and payoff (i.e. wage minus effort cost) for agents exerting tasks subject to moral hazard. By contrast, the effect on agents with verifiable effort is ambiguous. Greater inequality aversion does not necessarily mean higher wages as compensation. The reason is that these workers' equilibrium effort may decrease, remain constant or even increase, depending on whether effort levels are complements or substitutes across tasks in the principal's revenue function. Nevertheless, payoff differences decrease with the extent of inequality aversion. Wage differences also decrease unless tasks are strongly complementary.

We also analyze the implications of an improvement in the monitoring technology. Better monitoring or more informative performance measures reduce the marginal cost of providing incentives to category 1 agents. As a result, the firm requires that these agents exert more effort. If this also leads to a higher payoff for these workers, then the payoff for the other category of workers must also increase due to the larger inequality premium. However, it does so to a lesser extent so that overall inequality is larger.

There are several recent papers analyzing contracts with inequality averse agents. Maybe the work most closely related to ours is Bartling and Siemens (2003) who analyze an environment with one principal and two agents. However, agents in that model are risk averse and symmetric (see also Itoh 2004), while in our paper they face a limited liability constraint and differ in the verifiability of their effort. Furthermore, their analysis is considerably less general in several aspects: agents perform the same task, there are only two effort levels and only two output realizations. Englmaier and Wambach (2003) analyze sharing rules when an inequity averse agent compares his payoff to that of the principal. Siemens (2003) analyzes optimal employment contracts in an adverse selection model. There are also some contributions that analyze inequality aversion in the context of team production (e.g., Demougin and Fluet 2003).

The paper is structured as follows. Section 2 introduces the basic model. Sections 3 and 4 analyze the effects of inequality aversion on effort levels, wages and payoffs. Section 5 expands the picture by adding monitoring to the model. Finally, in the concluding section we discuss economic applications, in particular cross-country differences in productivity and mergers among firms with different corporate cultures.

\section{The model}

We consider a two-task work environment, assuming for simplicity that each task occupies a single agent. The value of output for the firm is $v\left(e_{1}, e_{2}\right)$, an increasing and concave function where $e_{i} \in \mathbb{R}^{+}$is the effort in task $i$ or equivalently the effort of agent $i, i=1,2$. Later in the text, we further char- 
acterize $v\left(e_{1}, e_{2}\right)$ in terms of whether inputs are substitutes or complements. All parties are risk-neutral and exerting effort in task $i \operatorname{costs} c_{i}\left(e_{i}\right)$. We impose the standard assumptions $c_{i}^{\prime}\left(e_{i}\right), c_{i}^{\prime \prime}\left(e_{i}\right)>0$ for $e_{i}>0, c_{i}(0)=c_{i}^{\prime}(0)=0$ and $\lim _{e_{i} \rightarrow \infty} c_{i}^{\prime}\left(e_{i}\right)=\infty$, which ensure an interior solution.

Tasks differ in the verifiability of effort. We assume $e_{2}$ is verifiable. The principal therefore offers agent 2 a contract specifying a fixed wage payment $w$ and the desired effort level, leading to the payoff

$$
\pi_{2}=w-c_{2}\left(e_{2}\right) .
$$

By contrast, neither the value of output nor the effort of agent 1 are verifiable, implying moral hazard with respect to the first task. However, the parties observe a contractible signal $s \in\{0,1\}$ where $s=1$ is favorable information about $e_{1}$ (see Milgrom 1981). ${ }^{2}$ We denote with $p\left(e_{1}\right)$ the probability of the favorable outcome given the agent's effort, with $p^{\prime}\left(e_{1}\right)>0$ and $p^{\prime \prime}\left(e_{1}\right) \leq 0 .{ }^{3}$ Given the binary nature of the signal, the incentive contract for agent 1 reduces to a fixed payment $F$ and a bonus $b$ which the agent receives when $s=1$. Agent 1's expected payoff is therefore

$$
\pi_{1}=F+p\left(e_{1}\right) b-c_{1}\left(e_{1}\right) .
$$

Workers are assumed to be financially constrained, otherwise the firstbest would be feasible as is well known. To economize on notation, we simply assume that wages must be non negative. Similarly, the agents' reservation utility is set equal to zero.

Inequality aversion captures the idea that a worker's well-being depends on how his expected payoff compares to that of co-workers. Specifically, as in Fehr and Schmidt (1999), agent $i$ 's utility is written as

$$
u_{i}\left(\pi_{i}, \pi_{j}\right)=\pi_{i}-\beta_{i} \max \left[\pi_{j}-\pi_{i}, 0\right]-\gamma_{i} \max \left[\pi_{i}-\pi_{j}, 0\right] .
$$

The second term on the right hand side is the disutility from disadvantageous inequality. Parameter $\beta_{i} \geq 0$ may be interpreted as the propensity for envy. The agent is 'envious' in the sense that his utility is reduced if he receives a lower expected payoff than the other agent. The third term is the disutility from advantageous inequality, with $\gamma_{i} \geq 0$ as the parameter for empathy. An agent feels 'empathy' if his utility is reduced when he receives a higher payoff than the other agent. We assume $\gamma_{i}<1$ so that agents experiencing empathy nevertheless prefer that their own payoff increases, even

\footnotetext{
${ }^{2}$ The assumption $s \in\{0,1\}$ is without loss of generality, as in the risk-neutral agency problem all relevant information from a mechanism design point of view can be summarized by a binary statistic (see, e.g., Kim 1997).

${ }^{3}$ These conditions guarantee that the agent's problem is well behaved. They are equivalent to considering binary signals satisfying MLRC and CDFC within the class of differentiable signals with constant support.
} 
when this also increases inequality. To simplify notation in what follows, we write

$$
u_{i}\left(\pi_{i}, \pi_{j}\right)=\pi_{i}-\alpha_{i}\left(\pi_{j}-\pi_{i}\right), \text { with } \alpha_{i}=\left\{\begin{array}{lll}
\beta_{i} & \text { if } & \pi_{i} \leq \pi_{j} \\
-\gamma_{i} & \text { if } & \pi_{i}>\pi_{j} .
\end{array}\right.
$$

The firm maximizes the value of output net of payments to the agents. Thus, it solves

$$
\max _{\left\{e_{1}, e_{2}, w, F, b\right\}} v\left(e_{1}, e_{2}\right)-w-F-b p\left(e_{1}\right),
$$

subject to participation of agents 1 and 2, incentive compatibility for the non-verifiable effort of agent 1 , as well as limited liability:

$$
\begin{aligned}
\pi_{1}-\alpha_{1}\left(\pi_{2}-\pi_{1}\right) & \geq 0, & & \left(\mathrm{PC}_{1}\right) \\
\pi_{2}-\alpha_{2}\left(\pi_{1}-\pi_{2}\right) & \geq 0, & & \left(\mathrm{PC}_{2}\right) \\
p^{\prime}\left(e_{1}\right) b-c_{1}^{\prime}\left(e_{1}\right) & =0, & & \left(\mathrm{IC}_{1}\right) \\
w, F, F+b & \geq 0 . & & (\mathrm{LL})
\end{aligned}
$$

Equation $\left(\mathrm{IC}_{1}\right)$ is the incentive compatibility condition for agent 1 and follows from

$$
e_{1}=\arg \max _{\tilde{e}_{1}} F+p\left(\tilde{e}_{1}\right) b-c_{1}\left(\tilde{e}_{1}\right)-\alpha_{1}\left[w-c_{2}\left(e_{2}\right)-F-p\left(\tilde{e}_{1}\right) b+c_{1}\left(\tilde{e}_{1}\right)\right] .
$$

From $\left(\mathrm{IC}_{1}\right)$ we can solve for the bonus,

$$
b=\frac{c_{1}^{\prime}\left(e_{1}\right)}{p^{\prime}\left(e_{1}\right)},
$$

and write the expected bonus as

$$
B\left(e_{1}\right) \equiv \frac{p\left(e_{1}\right) c_{1}^{\prime}\left(e_{1}\right)}{p^{\prime}\left(e_{1}\right)} .
$$

Observe that the bonus for agent 1 is independent of the inequality aversion parameters, given the required level of effort. Noting that $b>0$, and since $w \geq 0$ follows from agent 2's participation constraint, the limited liability constraints reduce to $F \geq 0$. After substitution, the Lagrangian becomes

$$
\begin{aligned}
\mathcal{L}(\cdot)= & v\left(e_{1}, e_{2}\right)-w-F-B\left(e_{1}\right) \\
& +\lambda\left(F+B\left(e_{1}\right)-c_{1}\left(e_{1}\right)-\alpha_{1}\left[w-c_{2}\left(e_{2}\right)-F-B\left(e_{1}\right)+c_{1}\left(e_{1}\right)\right]\right) \\
& +\mu\left(w-c_{2}\left(e_{2}\right)-\alpha_{2}\left[F+B\left(e_{1}\right)-c_{1}\left(e_{1}\right)-w+c_{2}\left(e_{2}\right)\right]\right)+\xi F .
\end{aligned}
$$


Given an interior solution, equilibrium values satisfy the following firstorder conditions with respect to $e_{1}, e_{2}, w$ and $F$, together with the complementary slackness conditions and non-negativity of multipliers $\lambda, \mu, \xi$ :

$$
\begin{aligned}
v_{e_{1}}-c_{1}^{\prime}\left(e_{1}\right)\left[\lambda\left(1+\alpha_{1}\right)-\mu \alpha_{2}\right]-B^{\prime}\left(e_{1}\right)\left[1-\lambda\left(1+\alpha_{1}\right)+\mu \alpha_{2}\right] & =0, \\
v_{e_{2}}+c_{2}^{\prime}\left(e_{2}\right)\left[\lambda \alpha_{1}-\mu\left(1+\alpha_{2}\right)\right] & =0, \\
-1-\lambda \alpha_{1}+\mu\left(1+\alpha_{2}\right) & =0, \\
-1+\lambda\left(1+\alpha_{1}\right)-\mu \alpha_{2}+\xi & =0,
\end{aligned}
$$

where $v_{e_{i}}$ denotes the partial derivative $\partial v\left(e_{1}, e_{2}\right) / \partial e_{i}$. We first derive two lemmas which greatly simplify the characterization of the equilibrium.

Lemma 1 The participation constraint of agent 2 always binds and $\pi_{1} \geq$ $\pi_{2}$, so that $\alpha_{1} \leq 0$ and $\alpha_{2}>0$.

Proof. See Appendix.

In words, if inequality aversion matters with respect to the contracts offered by the firm, this can only be due to the fact that agent 2, the worker with the observable effort, is envious of agent 1 and possibly also because agent 1 feels empathy for agent 2. Of course, the issue of envy or empathy can be relevant only if payoffs are unequal in equilibrium.

Lemma 2 The participation constraint of agent 1 never binds and $F=0$.

Proof. See Appendix.

Intuitively, agent 1 gets a rent due to the moral hazard problem and because of his binding limited liability constraint. Given $F=0$, this agent's payment reduces to the bonus $b$ paid in the case of favorable realizations of the signal. Recalling that the bonus depends only on the required effort and not on inequality aversion, the extent to which agent 1 feels empathy does not directly affect the contract he is offered, although empathy will reduce his utility and hence his actual rent. In the proof of the lemma, the fact that the rent remains positive despite empathy is shown to follow from the assumption $\alpha_{1}>-1$; that is, an agent prefers that his own payoff increases even if this also increases inequality. To complete the preceding results, we show that agent 1's payoff is indeed strictly greater than that of agent 2 .

Proposition 1 In equilibrium, $u_{1}>u_{2}$ and $\pi_{1}>\pi_{2}$.

The first statement follows directly from the lemmas. Using (4), $u_{1}>u_{2}$ is equivalent to

$$
\pi_{1}\left(1+\alpha_{1}+\alpha_{2}\right)>\pi_{2}\left(1+\alpha_{1}+\alpha_{2}\right),
$$

where $1+\alpha_{1}+\alpha_{2}>0$ since $\alpha_{1}>-1$ and $\alpha_{2}>0$, thereby implying $\pi_{1}>\pi_{2}$. 


\section{Effort and inequality aversion}

From lemma 1 we know that the participation constraint of agent 2 binds. Hence, we can solve $\mathrm{PC}_{2}$ for the wage

$$
w=c_{2}\left(e_{2}\right)+\frac{\alpha_{2}}{1+\alpha_{2}}\left[B\left(e_{1}\right)-c_{1}\left(e_{1}\right)\right] .
$$

Agent 2 is compensated for his effort cost and for the disutility he suffers from the larger net payoff earned by agent 1 . We henceforth refer to the latter term as the 'inequality premium'.

Using (14) and lemma 2, the principal's maximization problem can be restated as

$$
\max _{\left\{e_{1}, e_{2}\right\}} v\left(e_{1}, e_{2}\right)-c_{2}\left(e_{2}\right)-\frac{\alpha_{2}}{1+\alpha_{2}}\left[B\left(e_{1}\right)-c_{1}\left(e_{1}\right)\right]-B\left(e_{1}\right) .
$$

The first term represents the benefits of inducing effort. The next two terms are the wage of agent 2 . The final term is the expected bonus paid to agent 1 , who is compensated for his effort cost $c_{1}\left(e_{1}\right)$ and receives the net payoff $B\left(e_{1}\right)-c_{1}\left(e_{1}\right)$.

The first order conditions with respect to $e_{1}$ and $e_{2}$ are

$$
\begin{aligned}
v_{e_{1}}\left(e_{1}, e_{2}\right)+\left(\frac{\alpha_{2}}{1+\alpha_{2}}\right) c_{1}^{\prime}\left(e_{1}\right)-\left(1+\frac{\alpha_{2}}{1+\alpha_{2}}\right) B^{\prime}\left(e_{1}\right) & =0 \\
v_{e_{2}}\left(e_{1}, e_{2}\right)-c_{2}^{\prime}\left(e_{2}\right) & =0 .
\end{aligned}
$$

It follows immediately that the empathy parameter of agent $1, \alpha_{1}$, has no effect on equilibrium values. The reason is simply that this agent's participation constraint does not bind, as shown in the preceding section. Empathy reduces the agent's utility, but does not affect the cost to the firm of inducing effort. Thus, it is only agent 2's propensity for envy, $\alpha_{2}$, that will matter in equilibrium. Accordingly, when we refer to an increase in inequality aversion, we shall mean an increase in the propensity for envy, irrespective of whether the propensity for empathy also increases.

A larger $\alpha_{2}$ makes it more costly for the principal to provide incentives to agent 1 , since it increases the compensation that must be paid to the envious agent 2 . The firm therefore adjusts by requiring less effort from agent 1 , which means a lower powered contract with a smaller bonus. Differentiating the equilibrium conditions and applying Cramer's rule yields (see Appendix),

$$
\frac{d e_{1}}{d \alpha_{2}}=\varphi\left(v_{e_{2} e_{2}}-c_{2}^{\prime \prime}\right)<0,
$$

where

$$
\varphi \equiv \frac{\left(\frac{1}{\left(1+\alpha_{2}\right)^{2}}\right)\left(B^{\prime}-c_{1}^{\prime}\right)}{\left[v_{e_{1} e_{1}}+\left(\frac{\alpha_{2}}{1+\alpha_{2}}\right) c_{1}^{\prime \prime}-\left(1+\frac{\alpha_{2}}{1+\alpha_{2}}\right) B^{\prime \prime}\right]\left(v_{e_{2} e_{2}}-c_{2}^{\prime \prime}\right)-\left(v_{e_{1} e_{2}}\right)^{2}}>0
$$


and where $v_{e_{i} e_{j}}$ denotes the cross partial derivative.

To see that the signs are correct, note that the denominator in (19) is positive from the second-order condition for a maximum. ${ }^{4}$ From the definition of the expected bonus and the curvature assumptions, it is easily verified that $B^{\prime}\left(e_{1}\right)>c_{1}^{\prime}\left(e_{1}\right)$. The signs then follow from the concavity of the output function and the convexity of the cost functions.

Turning to agent 2, observe from (14) that a larger $\alpha_{2}$ increases the inequality premium, which depends on $e_{1}$, but does not directly affect the marginal costs of inducing effort $e_{2}$. However, there is an indirect effect if $v_{e_{1} e_{2}} \neq 0$, which results from changes in the equilibrium effort of agent 1 . If $v_{e_{1} e_{2}}>0$, then as $e_{1}$ falls so do marginal returns to the complementary input $e_{2}$; hence a lower $e_{2}$ becomes optimal. By contrast, if $v_{e_{1} e_{2}}<0$, then the lower $e_{1}$ increases marginal returns to $e_{2}$ and requiring more effort from agent 2 becomes optimal. Formally, again using Cramer's rule,

$$
\frac{d e_{2}}{d \alpha_{2}}=-\varphi v_{e_{1} e_{2}} .
$$

Finally, we show that more inequality aversion reduces total output in equilibrium or equivalently that it leads to a fall in the average productivity of labor (measured as average per-worker output). Differentiating the value of output function,

$$
\begin{aligned}
\frac{d v\left(e_{1}, e_{2}\right)}{d \alpha_{2}} & =v_{e_{1}} \frac{d e_{1}}{d \alpha_{2}}+v_{e_{2}} \frac{d e_{2}}{d \alpha_{2}} \\
& =\varphi\left(v_{e_{1}} v_{e_{2} e_{2}}-v_{e_{2}} v_{e_{1} e_{2}}-v_{e_{1}} c_{2}^{\prime \prime}\right)<0,
\end{aligned}
$$

where the sign of the expression in parenthesis follows from the concavity of the output function. ${ }^{5}$ We summarize the results of this section in the following proposition.

Proposition 2 More inequality aversion reduces equilibrium output and the effort of agent 1 . The effort of agent 2 decreases (increases) if the cross derivative $v_{e_{1} e_{2}}$ is positive (negative).

\section{Wages and payoffs}

We now analyze how inequality aversion affects wages and payoff differences. Total differentiation of the expression for agent 2's wage in (14) yields

$$
\frac{d w}{d \alpha_{2}}=\frac{B\left(e_{1}\right)-c_{1}\left(e_{1}\right)}{\left(1+\alpha_{2}\right)^{2}}+\left(\frac{\alpha_{2}}{1+\alpha_{2}}\right)\left[B^{\prime}\left(e_{1}\right)-c_{1}^{\prime}\left(e_{1}\right)\right] \frac{d e_{1}}{d \alpha_{2}}+c_{2}^{\prime}\left(e_{2}\right) \frac{d e_{2}}{d \alpha_{2}} .
$$

\footnotetext{
${ }^{4}$ The denominator is the determinant of the Hessian of the objective function, which must be positive for a regular interior maximum.

${ }^{5}$ Differentiating the marginal rate of substitution, the isoquant has the correct curvature if

$$
\frac{d}{d e_{2}}\left(-\frac{d e_{1}}{d e_{2}}\right)=\frac{d}{d e_{2}}\left(\frac{v_{e_{2}}}{v_{e_{1}}}\right)=\frac{v_{e_{1}} v_{e_{2} e_{2}}-v_{e_{2}} v_{e_{1} e_{2}}}{v_{e_{1}}^{2}}<0 .
$$
}


Recall that agent 2's wage consists of the inequality premium and the compensation for effort cost. The first term in (22) describes the direct effect of an increase in $\alpha_{2}$; that is, the increase of agent 2's inequality premium when holding $e_{1}$ fixed. The second term is the indirect effect on the inequality premium that works via the induced change in $e_{1}$. In particular, as $e_{1}$ falls, the net payoff $B\left(e_{1}\right)-c_{1}\left(e_{1}\right)$ of agent 1 decreases, implying that there is less to be envious about. Accordingly, this effect reduces agent 2's inequality premium. Without a further specification of functional forms it is therefore unclear whether changes in $\alpha_{2}$ increase or reduce the inequality premium. Finally, from proposition 2 we know that $e_{2}$ remains unchanged only if $v_{e_{1} e_{2}}=0$. In all other cases there will be a third effect as changes in $\alpha_{2}$ affect agent 2's effort and therefore his effort cost.

Despite the ambiguous effect of inequality aversion on the wage and payoff of agent 2, payoff differentials always decrease in $\alpha_{2}$. This is also the case for wage differentials, unless $v_{e_{1} e_{2}}$ has a large negative value. The reason is that the 'wage' of agent 1 - the expected bonus $B\left(e_{1}\right)$ - as well as his payoff unambiguously decrease in $\alpha_{2}$ and this effect usually dominates.

Substituting from (1), (2) and (14), the payoff differential is given by

$$
\pi_{1}-\pi_{2}=\frac{B\left(e_{1}\right)-c_{1}\left(e_{1}\right)}{1+\alpha_{2}} .
$$

Total differentiation yields

$$
\frac{d\left(\pi_{1}-\pi_{2}\right)}{d \alpha_{2}}=\frac{B^{\prime}\left(e_{1}\right)-c_{1}^{\prime}\left(e_{1}\right)}{1+\alpha_{2}} \frac{d e_{1}}{d \alpha_{2}}-\frac{B\left(e_{1}\right)-c_{1}\left(e_{1}\right)}{\left(1+\alpha_{2}\right)^{2}}<0 .
$$

The intuition is simply that payoff differentials become more costly as inequality aversion increases. The wage differential is obtained by adding $c_{1}\left(e_{1}\right)-c_{2}\left(e_{2}\right)$ to $(23)$. Obviously, agent 1's effort and associated costs decrease in $\alpha_{2}$. Therefore, unless the effort cost of agent 2 falls by a substantially larger amount, which is only possible if $v_{e_{1} e_{2}}>0$ so that $d e_{2} / d \alpha_{2}<0$ (see proposition 2), wage differentials must also decrease. We summarize the results in the following proposition.

Proposition 3 More inequality aversion reduces the wage and payoff of agent 1 and leads to smaller payoff differences between agents. Wage differences also decrease, unless $e_{1}$ and $e_{2}$ are strongly complementary.

\section{$5 \quad$ Monitoring and spillovers}

The consideration of inequality aversion leads to interesting feed-back effects. For instance, suppose that for some exogenous reason the technology used to monitor the category 1 worker improves. Improvements in information 
technology suggest that such a development may actually have taken place over the last two decades or so (see Garicano 2000).

In the absence of inequality aversion, this would only affect the agent who receives an incentive contract. This changes once we allow for inequality aversion. Let $\theta$ represent the monitoring technology. A better technology affects the probability with which a good signal is observed. As a result, the expected bonus $B\left(e_{1}, \theta\right)$ for inducing a given effort level now becomes a function of $\theta$. Intuitively, with better monitoring the firm can elicit a desired effort level with a smaller expected bonus. Furthermore, the marginal cost to the firm of inducing additional effort should decrease in $\theta$. Therefore, we assume $B_{\theta}\left(e_{1}, \theta\right)<0$ and $B_{e_{1} \theta}\left(e_{1}, \theta\right)<0 .{ }^{6}$

We first determine the effect of $\theta$ on agent 1's payoff. Total differentiation yields

$$
\frac{d \pi_{1}}{d \theta}=B_{\theta}+\left(B_{e_{1}}-c_{1}^{\prime}\right) \frac{d e_{1}}{d \theta}
$$

where

$$
\frac{d e_{1}}{d \theta}=\frac{\left(1+\frac{\alpha_{2}}{1+\alpha_{2}}\right)\left(v_{e_{2} e_{2}}-c_{2}^{\prime \prime}\right) B_{e_{1} \theta}}{\left[v_{e_{1} e_{1}}+\left(\frac{\alpha_{2}}{1+\alpha_{2}}\right) c_{1}^{\prime \prime}-\left(1+\frac{\alpha_{2}}{1+\alpha_{2}}\right) B_{e_{1} e_{1}}\right]\left(v_{e_{2} e_{2}}-c_{2}^{\prime \prime}\right)-\left(v_{e_{1} e_{2}}\right)^{2}}>0 .
$$

The latter, again applying Cramer's rule, is obtained from the equilibrium conditions (16) and (17) rewritten so as to incorporate monitoring (the denominator in (26) is positive by the second-order condition). As in the preceding section, the effect on $e_{2}$ depends solely on the sign of the cross derivative $v_{e_{1} e_{2}}$.

A better monitoring technology has two effects on agent 1's payoff. First, the bonus that is required to induce a desired effort level falls. Secondly, better monitoring technology implies that it becomes optimal for the principal to induce more effort. As a result, the overall effect on the agent's payoff is ambiguous. ${ }^{7}$

Turning to agent 2's payoff, note that from (1), (2) and (14),

$$
\pi_{2}=\left(\frac{\alpha_{2}}{1+\alpha_{2}}\right) \pi_{1}
$$

The payoff of agent 2 is simply his inequality premium, by which he is compensated for envying the payoff of agent 1. Obviously, the required compensation increases in agent 1's payoff and this spillover is larger the greater the degree of inequality aversion $\alpha_{2}$. The next result follows straightforwardly.

\footnotetext{
${ }^{6}$ See Demougin and Fluet (2001) for a general formulation.

${ }^{7}$ To provide an example, $\pi_{1}$ increases if $c_{1}\left(e_{1}\right)=0.5 e_{1}^{2}$ and $p\left(e_{1}, \theta\right)=e_{1}^{\theta}$, where $e_{1}, \theta \in$ $[0,1]$. See Demougin and Fluet (2001) for a justification of this specification of monitoring technology.
} 
Proposition 4 If an improvement in the technology to monitor agent 1 increases (decreases) the payoff of this agent, then the payoff of agent 2 and payoff differences also increase (decrease). Spillovers are greater, the greater the degree of inequality aversion.

\section{Concluding remarks and discussion}

This paper has analyzed a simple two-task environment in which a firm employs two wealth constrained agents. For agent 2, effort is verifiable, while for agent 1 it is not. Accordingly, only agent 1 receives an incentive contract, which leads to a positive rent and a payoff that the other agent resents. Inequality aversion affects the optimal contracts of both agents. In particular, more inequality aversion on the part of agent 2 reduces the effort, wage and payoff of agent 1 . It also leads to a compression of payoffs. If the principal's revenue is additively separable in the agents' effort, then the effort of agent 2 remains unchanged, but wage differences decrease. Finally, an improvement in the monitoring technology affects the payoff of both agents in the same direction, but effects on agent 1 are more pronounced.

The analysis may help understand differences in productivity and wage spread across countries with different cultural norms. For example, there is some empirical evidence that preferences for a more equal income distribution are stronger in Western Europe than they are in the United States (Corneo 2001; Alesina, Tella, and MacCulloch 2003; Schwarze and Härpfer 2003). There is also evidence that productivity is lower in Western Europe than in the US (e.g. Hall and Jones 1999). Our paper provides a possible explanation for this pattern although there are, of course, alternative ones (e.g., Bental and Demougin 2003).

The analysis is also useful to understand problems that may arise in mergers because of different corporate cultures. Though corporate cultures are multifaceted constructs, one important aspect is the degree to which employees find an unequal income distribution acceptable. For example, one reason why the merger between Daimler Benz and Chrysler Corporation started off rocky was that senior executives at Daimler earned a lot less than their Chrysler counterparts. Even Jürgen Schrempf, CEO of DaimlerChrysler, acknowledged "it's a major problem" (Schellhardt 1999). To narrow the gap, pay packages to Daimler managers were substantially increased.

This pattern nicely conforms with our analysis. For instance, consider the merger between two firms, each of which has a structure as described in the present paper. Suppose employees in firm $H$ are more inequality averse than those in firm $L$. Unless there are substantial differences in revenue or effort cost functions, firm $L$ would have paid higher wages to and required more effort from category 1 employees than firm $H$ (by proposi- 
tion 2). Moreover, firm $L$ would have been characterized by larger payoff differences (by proposition 3).

To focus on merger costs that arise from inequality aversion, consider the costs of implementing the effort levels that existed before the merger. In our simplified framework it seems reasonable to assume that employees will compare their payoff with that of the highest paid employee in the merged firm. Accordingly, the wage of the type 1 employee in firm $H$ will increase because he now envies the type 1 employee in firm $L$. Similarly, the wage of the type 2 employee in firm $H$ also increases because the difference between his payoff and that of the best paid employee has increased. More so, his wage would even increase if he continued to compare himself to the payoff of the type 1 employee in his original firm.

Note that there is no opposite effect in the other firm, where the costs of implementing pre-merger effort levels remain constant. Accordingly, our analysis predicts an upward adjustment of wages in the merged firm, just as it happened in the DaimlerChrysler example. Obviously, this discussion neglects that firms may adjust effort levels after the merger. Furthermore, the merger may have positive effects on the revenue function. Nevertheless, the analysis shows that it is often not possible for the merged firm to simply replicate the behavior of the previously separate firms if different corporate cultures continue to prevail.

\section{Appendix}

Proof of Lemma 1. Suppose, contrary to the first claim in the lemma, that $\mu=0$. Then by (11) $\lambda \alpha_{1}<0$ so that $\lambda>0$ and $\alpha_{1}<0$. Hence, $\mathrm{PC}_{1}$ binds and $u_{1}=0$. Agent 2 's participation constraint can therefore be written as $u_{1} \leq u_{2}$. Upon substitution from (4),

$$
\pi_{1}\left(1+\alpha_{1}+\alpha_{2}\right) \leq \pi_{2}\left(1+\alpha_{1}+\alpha_{2}\right) .
$$

From the definition of the $\alpha_{i}$ 's, it is not possible for $\alpha_{1}$ and $\alpha_{2}$ to be both negative. Hence $\alpha_{2}>0$. Furthermore, $\alpha_{1}>-1$ by assumption. Therefore, $1+\alpha_{1}+\alpha_{2}>0$ and (28) implies $\pi_{2} \geq \pi_{1}$. But this in turn implies $\alpha_{1} \geq 0$ (see 4). Hence $\lambda \alpha_{1} \geq 0$, a contradiction.

Furthermore, given $\mu>0$ the participation constraint of agent 2 binds and $u_{1} \geq u_{2}$. Accordingly, the inequality sign in (28) is reversed, which proves the second claim in the lemma. Therefore, the only relevant forms of inequality aversion are 'empathy' $\left(\alpha_{1} \leq 0\right)$ for agent 1 and 'envy' $\left(\alpha_{2}>0\right)$ for agent 2 .

Proof of Lemma 2. Suppose to the contrary that $\mathrm{PC}_{1}$ binds. Solving $\mathrm{PC}_{2}$ for $\pi_{2}$ and substitution into $\mathrm{PC}_{1}$ yields

$$
\pi_{1}\left(1+\alpha_{1}\right)-\frac{\alpha_{1} \alpha_{2}}{1+\alpha_{2}} \pi_{1}=0 .
$$


Since $1+\alpha_{1}>0$ and given that $\alpha_{1} \alpha_{2} /\left(1+\alpha_{2}\right) \leq 0$ by lemma 1 , this can only be satisfied if $\pi_{1}=0$. Denote the signal elasticity by $\epsilon\left(e_{1}\right)=$ $e_{1} p^{\prime}\left(e_{1}\right) / p\left(e_{1}\right)$ and observe that $\epsilon\left(e_{1}\right) \in[0,1]$ by concavity of $p\left(e_{1}\right)$. Upon substitution and noting that $e_{1} c_{1}^{\prime}\left(e_{1}\right)>c_{1}\left(e_{1}\right)$ by strict convexity of the cost function,

$$
B\left(e_{1}\right)=\frac{e_{1} c_{1}^{\prime}\left(e_{1}\right)}{\epsilon\left(e_{1}\right)}>c_{1}\left(e_{1}\right),
$$

a contradiction to $\pi_{1}=0$ (see equation (2)). Finally, to prove $F=0$, note that from (11) and (12),

$$
\lambda=\frac{1+2 \alpha_{2}-\left(1+\alpha_{2}\right) \xi}{1+\alpha_{1}+\alpha_{2}} .
$$

Accordingly, a non-binding participation constraint for agent $1(\lambda=0)$ implies $\xi>0$, hence $F=0$.

Calculation of $d e_{1} / d \alpha_{2}$. Denoting the principal's objective function (15) by $F$ and applying Cramer's rule yields

$$
\frac{d e_{1}}{d \alpha_{2}}=-\frac{\operatorname{det}\left(\begin{array}{ll}
F_{e_{1} \alpha_{2}} & F_{e_{1} e_{2}} \\
F_{e_{2} \alpha_{2}} & F_{e_{2} e_{2}}
\end{array}\right)}{\operatorname{det}\left(\begin{array}{ll}
F_{e_{1} e_{1}} & F_{e_{1} e_{2}} \\
F_{e_{2} e_{1}} & F_{e_{2} e_{2}}
\end{array}\right)}=-\frac{F_{e_{1} \alpha_{2}} F_{e_{2} e_{2}}}{F_{e_{1} e_{1}} F_{e_{2} e_{2}}-\left(F_{e_{1} e_{2}}\right)^{2}} .
$$

Upon substitution, this yields (18) and (19). Calculation of $d e_{2} / d \alpha_{2}$ and $d e_{1} / d \theta$ proceeds in the same way.

\section{References}

Alesina, A., R. D. Tella, and R. MacCulloch (2003). Inequality and happiness: Are Europeans and Americans different? mimeo.

Bartling, B. and F. v. Siemens (2003). Inequity aversion and moral hazard with multiple agents. mimeo.

Bental, B. and D. Demougin (2003). Incentive contracts and total factor productivity. mimeo.

Brosnan, S. F. and F. B. Waal (2003). Monkeys reject unequal pay. Nature 425(18 September 2003), 297-299.

Camerer, C. (2003). Behavioral Game Theory. Princeton: Princeton University Press.

Corneo, G. G. (2001). Inequality and the state: Comparing U.S. and German preferences. Annales d'Economie et de Statistique (63-64), 283-296. 
Demougin, D. and C. Fluet (2001). Monitoring versus incentives. European Economic Review 45, 1741-1764.

Demougin, D. and C. Fluet (2003). Group vs. individual performance pay when workers are envious. CIRPEE Working Paper 03-18.

Englmaier, F. and A. Wambach (2003). Contracts and inequity aversion. CESifo Working Paper No. 809.

Fehr, E. and K. Schmidt (1999). A theory of fairness, competition, and cooperation. Quarterly Journal of Economics 114(3), 817-868.

Fehr, E. and K. Schmidt (2003). Theories of fairness and reciprocity Evidence and economic applications. In M. Dewatripont, L. Hansen, and S. Turnovsky (Eds.), Advances in Economics and Econometrics, pp. 208-257. Cambridge UK: Cambridge University Press.

Garicano, L. (2000). Hierarchies and the organization of knowledge in production. Journal of Political Economy 108(5), 874-904.

Hall, R. E. and C. I. Jones (1999). Why do some countries produce so much more output per worker than others? The Quarterly Journal of Economics 114(1), 83-116.

Itoh, H. (2004). Moral hazard and other-regarding preferences. Japanese Economic Review 55(1), 18-45.

Kim, S. (1997). Limited liability and bonus contracts. Journal of Economics and Management Strategy 6, 899-913.

Konow, J. (2003). Which is the fairest one of all? a positive analysis of justice theories. Journal of Economic Literature 61(4), 1188-1239.

Milgrom, P. (1981). Good news and bad news: Representation theorems and applications. Bell Journal of Economics 12, 380-391.

Schellhardt, T. D. (1999). Marriage of unequals upsets the honeymoon. Wall Street Journal Online. 16.12.1999.

Schwarze, J. and M. Härpfer (2003). Are people inequality averse, and do they prefer redistribution by the state? A revised version. IZA Discussion Paper No. 974.

Siemens, F. v. (2003). Fairness, adverse selection and employment contracts. mimeo. 